\title{
Stochastic Modeling Of Photovoltaic Cell Condition
}

\section{Grzegorz Trzmiel}

Faculty of Control, Robotics and Electrical Engineering, Poznan University of Technology Piotrowo 3A, 60-965 Poznan, Poland

e-mail: grzegorz.trzmiel@ put.poznan.pl

\begin{abstract}
The paper presents the author' original modification of the residual method in order to construct an efficient tool for assessing the condition of photovoltaic cells, in particular - panels made of amorphous cells which are characterized by significant random operation parameter changes. The solution constructed has been verified through experiments, which show the usefulness of the proposed methodology as it allows to minimize the risk of obtaining false diagnostic information in the process of assessing the condition of photovoltaic panels.
\end{abstract}

Keywords: photovoltaic cell; residuum; modeling; inefficiency; randomness;

\section{Introduction}

The problem of determining the reliability and condition of objects is a scientific matter that is currently and nowadays popular [17,33]. Examples of objects in the subject matter are photovoltaic panels. In the usage of photovoltaic panels it is particularly important to establish the temporal parameters of their equivalent circuit. Such parameters make it possible to estimate the panel inefficiency and its changes in time. The operation conditions for photovoltaic panels are random $[19,25,35]$.

The article is a continuation of the author's considerations in [30], which concerned the modeling of photovoltaic cells using measurement data .. Also presented in both works ([30], and the present) proposals were partly used in the work of joint authorship [10] about the influence of shading to operate PV installations.

In further considerations, the author used the residual method, which he verified for the purposes of the presented issue. The residual method is popular in many fields of science. It is used in research on animals and plants, eg. In the determination and confirmation of metabolic compounds in animal tissues [5] and in determining the residues of various types of substances include antibiotics in bovine milk [21], in liquid chromatography - tandem spectrometry in the detection of dozens of antibiotic residues in milk and meat [13] as well as validation and quality control processes and feed compositions [12]. In each of these examples, the residues method was adapted by its appropriate modification, often consisting in the extension of the base method or the introduction of new mathematical elements. Similar examples can be found in many other fields of science, e.g. in urban modeling of features of interesting phenomena on the example of Toronto [2], in analytical calculation of THD (Total Harmonic Distortion) communication devices, e.g. transmitters or power amplifiers [3], in risk estimation and assessment for the health of toxic metals and antibiotic residues in meat served in hospitals in Egypt [8], in the study of decomposition, flow and heat exchange in channels with flowing water using the Galerkin weighted residual method [1], in mathematics in the assessment of the finite part algebraically and logarithmically divergent integrals at infinity [7] or even for the assessment of noise in hyperspectral images [20]. The residual method is therefore popular in many different thematic areas. This article proposes to use this method in stochastic modeling of the state of PV cells. 
This makes it necessary to include the parameter randomness in the panel equivalent models $[4,24,34]$. In the deterministic view, the most popular ideal equivalent model for photovoltaic panels is the electric circuit presented on Figure 1.

If $I_{0}[\mathrm{~A}]$ - stands for the diode field-free, $q$ - for the elementary charge $\left(1,6 \cdot 10^{-19} \mathrm{C}\right), k_{B}-$ Boltzmann constant $\left(1,38 \cdot 10^{-23} \mathrm{~J} / \mathrm{K}\right), T\left[{ }^{\circ} \mathrm{C}\right]-$ temperature, the output current has the following value $[15,16,25]$ :

$$
I=I_{p h}-I_{D}=I_{p h}-I_{0}\left[\exp \left(\frac{q U}{k_{B}(T+273.15)}\right)-1\right]
$$

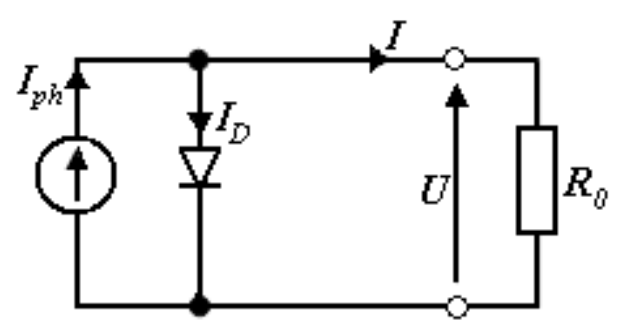

Fig. 1. Ideal equivalent circuit for a photovoltaic cell model with three parameters $[15,16,29]: R_{0}[\Omega]-$ load resistance, $I_{p h}[\mathrm{~A}]$ - current in the cell exposed to solar radiation, $I_{\mathrm{D}}[\mathrm{A}]$ - current in the diode with large surface area, $I[\mathrm{~A}]$ - load current, $U[\mathrm{~V}]$ - voltage decrease in the $R_{0}$ receiver

When the temperature $T$ grows, the voltage in the open circuit of the photovoltaic cell decreases, but the value of the short circuit current remains unchanged, which can be observed in practice as the decrease of the cell power [11,25].

The equation (1) for a photovoltaic cell with five parameters has the following form $[15,16,30,31]$ :

$I=I_{p h}-I_{0}\left\{\exp \left[\frac{q\left(U+I R_{S}\right)}{k_{B} T}\right]-1\right\}-\frac{U+I R_{S}}{R_{W}}$

The corresponding equivalent circuit is presented on Figure 2.

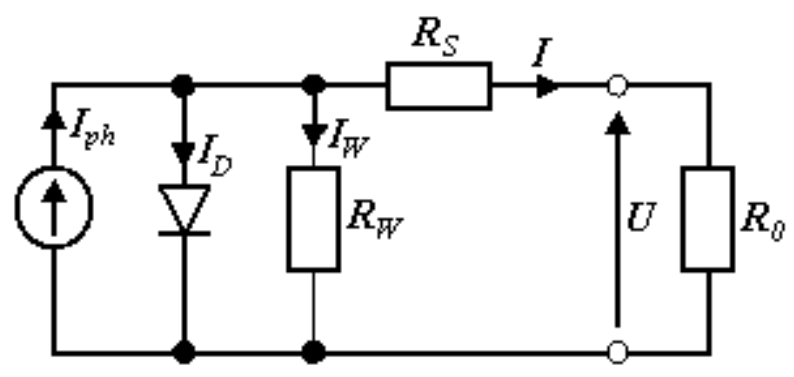

Fig. 2. Equivalent circuit for a photovoltaic cell model with five parameters $[15,27]: I_{W}[\mathrm{~A}]-$ shunt resistance current

The series resistance $R_{S}$ includes the values of contact resistance of the base as well as other cell layers. Shunt resistance $R_{w}$ represents the current leak along the cell edge. While designing photovoltaic cells, it is important to minimize the $R_{S}$ value and to achieve the highest possible value of $R_{w}$.

After assuming $R_{W}=\infty$ and $R_{S}=0$, the ideal three-parameter model is obtained. 
The operation of the equivalent circuit in random conditions can be illustrated by putting random values of the parameters of a single photovoltaic cell where the resultant current and voltage for the photovoltaic modules are respectively the sums of the current (for the parallel circuit) and voltage (for the series circuit) values of individual cells.

Using the „constant randomization" method for equation (1) or (2), one can obtain the probabilistic characteristics of the photovoltaic cell. For example, if the temperature changes randomly, the relation obtained for equation (1) is

$$
I=I_{p h}-I_{D}(t)
$$

where:

$$
I_{D}(t)=I_{D}[T(t)]
$$

and $T(t)$ is a stochastic process.

Due to the "hidden" dependencies described and captured in the equations above, the equations obtained are not very accurate. That is why, according to the author, a better model of the photovoltaic cell inefficiency series is the model obtained through the rolling comparison with the averaged model obtained by means of earlier measurements performed, for example, for a non-defective module. One of the analysis methods is the proposed method based on the definition of the processed residual.

\section{Materials and Methods}

\subsection{Modification of the Residual Method}

There are many residual definitions, including those of pseudo-residual. In the simplest residual assessment method, the result of measurements designated as $y$ is compared with the signal $\hat{y}$ generated by the model, generating the residual $r$ (ordinary residuals) [31]:

$$
r=\hat{y}-y
$$

In the ideal case when the object operates correctly, the residual value should be zero, and it should be different from zero as soon as a failure or inefficiency appears (Figure 3).

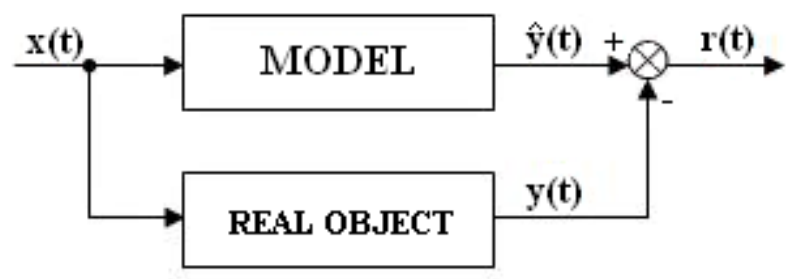

Fig. 3. Ideal scheme for the residual assessment method [23]: $x(t)$ - enforcements in a given moment in time

Residual values different from zero can also be observed in practice when the following occur [28]:

- model inaccuracies (showing linearity, for example in the sectional function of the output signal),

- interferences in the actual random measurement values. 
As a result of those, it becomes necessary to establish a certain area of model uncertainty for residual values round 0 [18].

A more objective mapping of the current residual value onto the state of the non-linear object under examination can be obtained through the conversion of the residual absolute value to the relative value $\delta r[\%]$ :

$$
\delta r=\frac{\hat{y}-y}{\hat{y}} \cdot 100
$$

or more accurately:

$$
\delta r_{m}=\left|\frac{\hat{y}-y}{\hat{y}}\right| \cdot 100
$$

Relative residual values guarantee a more accurate assessment of the current state, both in terms of quality and in terms of quantity. What is more, it can be assumed that residuals are variables randomly subject to the Gauss normal distribution $P(X)[24,26]$. This is confirmed by the curve obtained from measurements and calculations (Figure 4), determined on the basis of experimental data from the cell load range of $0-200 \Omega$ and its final model. The modeling error is here represented as the displacement of the bell curve peak to the left of the ideal value $\delta r=0$.

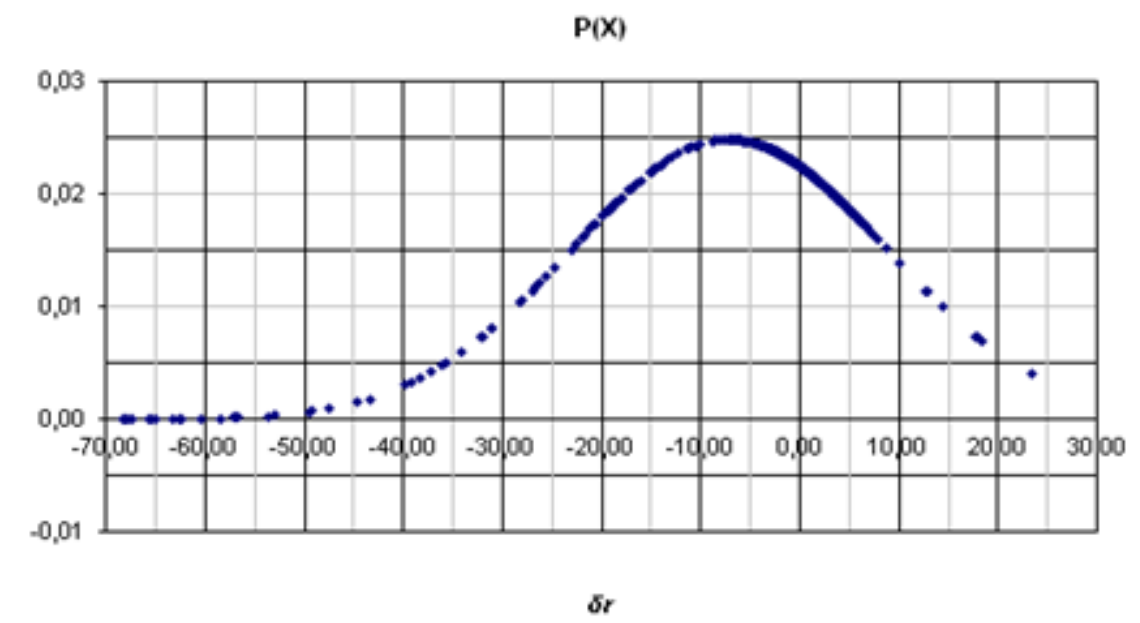

Fig. 4. Gauss curve for relative residual distribution $\delta r$ during modeling [31]

That is why a modification of the residual method through the introduction of the dynamic determination of alarm limits by appropriate transformation of the measured values has been proposed. Temporal values are transformed into discrete values, residual signals $\delta r_{j}(j-$ measurement number) are transformed by means of the following equation [9]:

$R_{j}=\left(1-e^{-\left(\frac{\delta r_{j}}{\sigma_{z}}\right)^{2}}\right) \cdot \delta r_{j}$

where: $R_{j}$-residual value after the modification, $\sigma_{z}$-standard deviation estimate for historical data describing correct object operation from the $\delta r_{j}$ values, whose absolute value (7) was higher than the standard deviation estimate $\sigma_{w}$ calculated for all the $\delta r_{j}$ data.

\subsection{Assessing Photovoltaic Cell Wear / Defects}


Residual values greater than zero after the modification can indicate a defect in the object under examination, but they can also signal something else.

In the next stage, the processed $R_{j}$ residuals are subject to averaging through the determination of moving average values $g_{j}$ with the dynamically calculated time horizon $N_{j}$ for every discrete time instant $j$ :

$g_{j}=\frac{\sum_{i=j-N_{j}}^{j} R_{i}}{N_{j}}$

After empirical verification, a 2-stage range of the $N_{j}$ horizon regulation was assumed. The default $N_{j}$ value is 5 , but when the condition (10) is satisfied, the value is 10 . Condition (10) means that if the value for a single relative residual $\delta r(6)$ is higher than the standard deviation value $\sigma_{w}$ determined for all the relative residuals given during normal operation (during modeling) then the time horizon in step $j$ is 10 ; otherwise it is 5 .

$N_{j}=5 \stackrel{N o}{\leftarrow}\left(\delta r_{j}>\sigma_{w}\right) \stackrel{\text { YES }}{\longrightarrow} N_{j}=10$

The decisive component (10) effectively limits the consequences of temporary changes in residual values caused by random factors, which has been empirically confirmed.

It is assumed that the limit $l_{j}$ is proportional to the model inaccuracy in a given discrete time instance $j$ :

$l_{j}=\sigma_{j}^{h}-R_{j}$

where: $\sigma_{j}^{h}$ - standard deviation estimate in the given time horizon $N_{j}$ for the original residuals $\delta r_{j}$.

Finally, the defect, wear, or other inefficiency detection condition can be obtained:

$R_{j}>l_{j}$

where: $R_{j}$ - estimate of the residual standard deviation that can be caused, for example, by a defect of the monitored object, $l_{j}$ - estimate of the standard deviation for residuals caused by model inaccuracy.

Satisfying the condition (12) does not constitute the full diagnosis of the damage of the examined panel. It is, however, a premise for further assessment verification in order to determine the seriousness of the inefficiency.

It is suggested to perform a verification of the initial assessment through establishing whether the value fits within the power range assumed for the panel operation.

According to the different works already published on the subject $[6,9,15,22]$, the approach is to use panels mostly in the generated power range $\left(P_{\max }-10 \% \cdot P_{\max } \div P_{\max }\right)$, and more rarely in $\left(P_{\max }-20 \% \cdot P_{\max } \div P_{\max }\right)$. What is more, it appears that during the panel operation in the range of high declining steepness of the $I=f(U)$ characteristics below $\left(P_{\max }-10 \% \cdot P_{\max } \div P_{\max }\right)$ even a small change in the load and in the random environmental conditions (e.g. temporary shading) can generate false high value residuals. That is why the final assessment of the panel inefficiency state should be confirmed after it is verified in the broader range of power fluctuations $\left(P_{\max }-10 \% \cdot P_{\max } \div P_{\max }\right)$. Whether a given measurement series falls into that range is determined by checking whether the condition is satisfied after being calculated with the use of the mathematical model of the $P$ power sample for the range specified above, which is also determined with the use of the model. 
The modifications introduced „smoothen” the photovoltaic cell condition assessment. Thus, they can help prevent temporary false alarms. Unfortunately, they also introduce an additional time delay in the process of detecting the wear or defect state. Considering, however, long exploitation periods for photovoltaic panels when they reach $90 \%$ of the rated power specified by the manufacturer, delaying diagnostic decisions should not lead to the increase of economical losses.

In the course of the research, it turned out that the inefficiency (wear) state of a photovoltaic panel $S_{\%}$ is directly proportional to the percentage average of the relative residual value:

$$
\left(\sigma_{r_{s r}} \leq 20 \% \cdot \mid \delta r_{s r}\right)_{n=10} \wedge\left(N_{j}=\text { const. }\right)_{n=10} \wedge R_{j}>l_{j} \stackrel{Y E S}{\longrightarrow} S_{\%}=\left(\delta r_{s r}\right)_{n=10}
$$

where: $n=10$ means satisfaction of all the conditions and performing calculations in the 10 last discrete steps.

On the basis of empirical dependencies (on the basis of histograms), it is assumed that the average relative residual value is calculated from the $n=10$ last steps providing that the time horizon $N_{j}$ does not change in those consecutive steps. What is more, the average value $\delta r_{s r}$

(14) obtained must be characterized with the standard deviation $\sigma_{r_{s r}}$ that is not higher than $20 \%$ of the average value module and condition (12) must be satisfied for the given set of samples measured [32].

$\delta r_{s r}=\frac{\sum_{i=j-n+1}^{j} \delta r}{n}$

Satisfying the detection condition (13) makes it possible to minimize the influence of individual serious errors resulting from local inaccuracies of the model or from random faults in the measurement samples. The value of the $S_{\%}$ parameter that is greater than zero can indicate that the cell is wearing out. The value of the parameter that is smaller than zero can be caused by inaccuracies in the measurements or in the model itself.

\section{Results and Discussion}

\subsection{Verification of the inefficiency detection method}

The detection method described above has been verified empirically on random measurement samples in real panel operation conditions. Parameters $y$ (real value) and $\hat{y}$ (model value) in equation (6) have been substituted with analogous current values of $I$ and $\hat{I}$.

Figure 5 shows the influence of shading random areas of the panel working surface on the current-voltage characteristics of its operation in the load range from 0 to $200 \Omega$.

Differences between the model curves (red and dark blue) result mainly from small differences in the temperature during the two measurement series. The measurements done with $60 \%$ shading of the panel working surface were performed when the temperature was about $2^{\circ} \mathrm{C}$ higher, although the lighting conditions were very similar and amounted to about $200-240 \mathrm{~W} / \mathrm{m}^{2}$.

Some interferences were modeled with the use of blinds. Shading a part of the panel surface simulates a failure of the part of the cell which can be caused by different external factors as well as wear [34]. Repeating the measurements multiple times for randomly selected panel areas has shown that the placement of the blind on a correctly working photovoltaic panel does not play any role in the results obtained. 


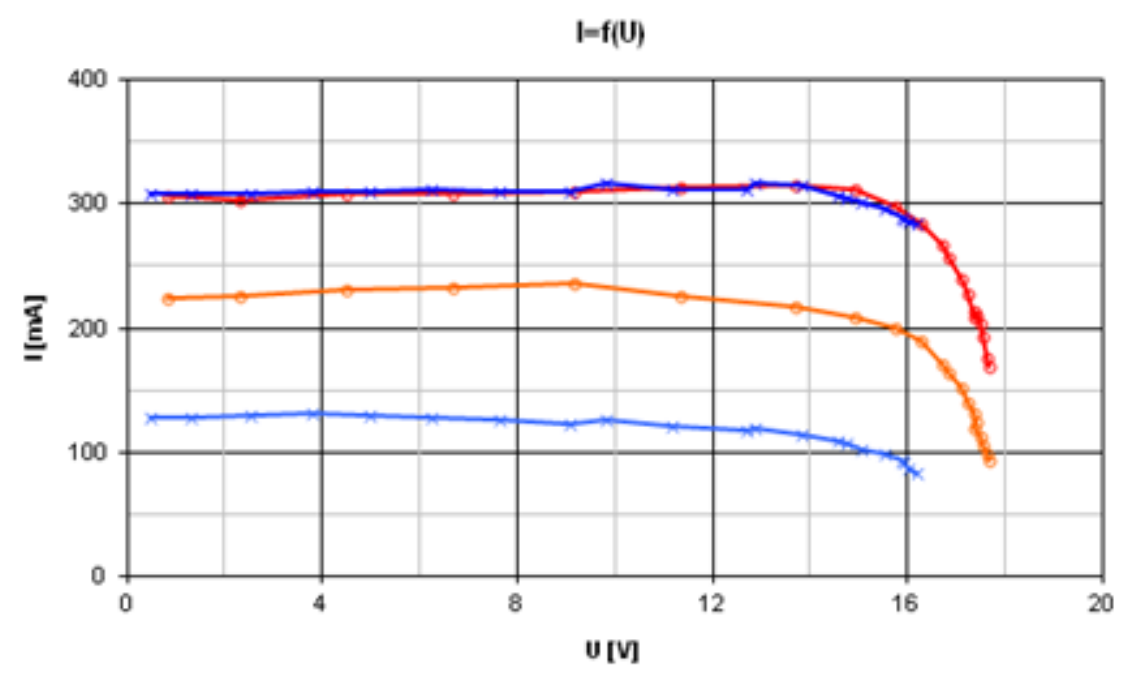

Fig. 5. Sample $I=f(U)$ characteristics of a photovoltaic panel, curves: red, dark blue - model values for a fully operational panel, orange - real values with the blind covering $30 \%$ of the panel surface, light blue - real values with the blind covering $60 \%$ of the panel surface [31]

For the case presented on Figure 5, the following measurement results were obtained:

- average malfunction $S_{\%}$ levels calculated for samples from the whole power fluctuation range $P$, without satisfying the condition (13) in their selection, the results obtained amounted to respectively: $2,716 \%$ with no blind, $34,897 \%$ with the $30 \%$ blind and 62,806 with the $60 \%$ blind,

- analogously to the above, the average values obtained when the condition (13) was satisfied were as follows: $0 \%$ with no blind, $32,627 \%$ with the $30 \%$ blind and $57,497 \%$ with the $60 \%$ blind.

The results obtained confirm the usefulness of the condition (13) in more precise determination of the malfunction state as using this criterion reduces the scatter band for the malfunction state around the expected values.

Table 1 shows analogous values of the malfunction state $S_{\%}$ obtained for other levels of the radiation power density $D_{r}$.

Table 1

Sample malfunction state values $S \%$ for different irradiance values $D_{r}$ for the full range of power variations

\begin{tabular}{|c|c|c|c|c|}
\hline \multirow{2}{*}{$D_{r}\left[\mathrm{~W} / \mathrm{m}^{2}\right]$} & \multirow{2}{*}{$\begin{array}{c}\text { Condition } \\
\text { satisfied }\end{array}$} & \multicolumn{3}{|c|}{$S \%[\%]$} \\
\cline { 2 - 5 } & NO & $-0,432$ & 31,328 & $60 \%$ blind \\
\hline \multirow{3}{*}{$120-150$} & YES & 0 & 30,872 & 58,291 \\
\cline { 2 - 5 } & NO & 2,036 & 41,351 & 64,794 \\
\hline \multirow{3}{*}{$200-210$} & YES & 0 & 37,831 & 63,810 \\
\cline { 2 - 5 } & NO & 13,605 & 56,021 & 71,470 \\
\hline \multirow{2}{*}{$370-400$} & YES & 2,790 & 42,364 & 65,871 \\
\cline { 2 - 5 } & NO & 18,302 & 56,017 & 76,713 \\
\hline \multirow{2}{*}{$490-560$} & YES & 7,740 & 45,350 & 70,180 \\
\cline { 2 - 5 } & & & & \\
\hline
\end{tabular}


Table 2

Sample values of the malfunction state $S \%$ for different irradiance values $D_{r}$ for $\left(P_{\max }-10 \% \cdot P_{\max } \div P_{\max }\right)$

\begin{tabular}{|c|c|c|c|c|}
\hline \multirow{2}{*}{$D_{r}\left[\mathrm{~W} / \mathrm{m}^{2}\right]$} & \multirow{2}{*}{$\begin{array}{c}\text { Condition }(13) \\
\text { satisfied }\end{array}$} & \multicolumn{3}{|c|}{$S \%[\%]$} \\
\cline { 3 - 5 } & NO & 2,098 & 32,163 & $60 \%$ blind \\
\hline \multirow{3}{*}{$120-150$} & YES & 0 & 28,382 & 50,443 \\
\cline { 2 - 5 } & NO & 0,652 & 40,005 & 70,706 \\
\hline \multirow{2}{*}{$200-210$} & YES & 0 & 33,504 & 65,836 \\
\cline { 2 - 5 } & NO & 1,799 & 33,382 & 65,304 \\
\hline \multirow{2}{*}{$200-240$} & YES & 0 & 29,467 & 61,084 \\
\hline \multirow{2}{*}{$370-400$} & NO & 1,528 & 43,787 & 70,008 \\
\cline { 2 - 5 } & YES & 0 & 34,124 & 62,318 \\
\hline \multirow{2}{*}{$490-560$} & NO & 0,558 & 42,911 & 74,291 \\
\cline { 2 - 5 } & YES & 0 & 35,126 & 70,922 \\
\hline
\end{tabular}

The analysis of the results, such as those presented in Table 1, made it possible to achieve a considerable improvement of the malfunction state assessment considering the detection condition (13). It was also discovered that the malfunction state values decrease in the direction of the actual percentage value of the blind used. The results presented above pertain to the whole range of variations for the examined characteristics and table 2 shows analogous results for the power range of $P_{\max }-10 \% \cdot P_{\max } \div P_{\max }$.

The sample data sets presented in Table 2 show that for the power range of $\left(P_{\max }-\right.$ $\left.10 \% \cdot P_{\max } \div P_{\max }\right)$ the errors in malfunction state assessment have decreased in number and that they amount to zero for panel operation without blinds considering the detection condition (13).

\section{Conclusions}

The argumentation and verification results presented above (as shown in Tables 1 and 2) confirm the usefulness of the method of malfunction state assessment developed by the author. It is particularly important while assessing the condition (malfunction state) of amorphous panels which are characterized by the highest random changes of operation parameters. That is why the method has been developed and confirmed by means of tests with the usage of the Shell ST20 amorphous panel. What is more, the method usefulness has been confirmed particularly during the verification of the mathematical model obtained. The methodology of the procedure can be successfully used for various applications of photovoltaic cells, including off-grid systems cooperating with energy storage.

\section{Conflict of Interests}

The author declare that there is no conflict of interests regarding the publication of this paper.

\section{References}

[1] Arani, A. A. A., Arefmanesh, A., \& Niroumand, A.: Investigation of fully developed flow and heat transfer through n-sided polygonal ducts with round corners using the Galerkin weighted 
residual method. Int. J. Nonlinear Anal. Appl, 9(1), 2018, 175-193, DOI: 10.22075/IJNAA.2017.10429.1502

[2] Batty, M., \& March, L.: The method of residues in urban modelling. Environment and Planning A, 8(2), 1976, 189-214., DOI: https://doi.org/10.1068/a080189

[3] Blagouchine, I. V., \& Moreau, E.: Analytic method for the computation of the total harmonic distortion by the Cauchy method of residues. IEEE Transactions on communications, 59(9), 2011, 2478-2491., DOI: 10.1109/TCOMM.2011.061511.100749

[4] Böhme J.F.: Stochastische Signale, Verlag Teubner, Stuttgart, Germany 1993

[5] Boison, J. O., Lee, S. C., \& Gedir, R. G.: A determinative and confirmatory method for residues of the metabolites of carbadox and olaquindox in porcine tissues. Analytica chimica acta, 637(12), 2009, 128-134, DOI: https://doi.org/10.1016/j.aca.2008.09.016

[6] Ciok Z.: Environmental protection in power - Volume XXIX of the series 'Main problems of modern technology', Polish Scientific Publishers PWN, Warsaw, Poland 2017

[7] De los Santos, J. D. C., \& Galapon, E.: The method of residues in the evaluation of finite part of algebraically and logarithmically divergent integrals at infinity. Proceedings of the Samahang Pisika ng Pilipinas, 2018

[8] El-Wehedy, S. E., Darwish, W. S., Tharwat, A. E., \& Hafez, A. E.: Estimation and health risk assessment of toxic metals and antibiotic residues in meats served at hospitals in Egypt. J Vet Sci Technol, 9(2), 2018, DOI: 10.4172/2157-7579.1000524

[9] Gautam N., Kaushika N.: Reliability evaluation of solar photovoltaic arrays, Solar Energy 2002, $\mathrm{N}^{\circ} 72 / 2$

[10] Głuchy D., Kurz D., Trzmiel G., The impact of shading on the exploitation of photovoltaic installations, Renewable Energy, vol. 153, p. 480-498, June 2020, DOI: https://doi.org/10.1016/j.renene.2020.02.010

[11] Ikegami T., Maezono T., Nakanishi F., Yamagata Y., Ebipara K.: Estimation of equivalent circuit parameters of PV module and its application to optimal operation of PV system, Solar Energy 2001, №67

[12] Jank, L., Martins, M. T., Arsand, J. B., Ferrão, M. F., Hoff, R. B., Barreto, F., \& Pizzolato, T. M.: An LC-ESI-MS/MS method for residues of fluoroquinolones, sulfonamides, tetracyclines and trimethoprim in feedingstuffs: validation and surveillance. Food Additives \& Contaminants: Part A, 35(10), 2018, 1975-1989, DOI: https://doi.org/10.1080/19440049.2018.1508895

[13] Jank, L., Martins, M. T., Arsand, J. B., Motta, T. M. C., Feijó, T. C., dos Santos Castilhos, T., ... \& Pizzolato, T. M.: Liquid chromatography-tandem mass spectrometry multiclass method for 46 antibiotics residues in milk and meat: development and validation. Springer: Food Analytical Methods, 10(7), 2017, 2152-2164, DOI: 10.1007/s12161-016-0755-4

[14] Jäger-Waldau A.: PV Status Report 2011, DG Joint Research Centre, European Commission, Italy 2011

[15] Kandyba A., Rodacki T.: Energy conversion in solar power (in polish), Silesian University of Technology Publisher, Gliwice, Poland 2000

[16] Kerr M., Cuevas A.: Generalized analysis of the illumination intensity vs. open-circuit voltage of solar cells, Solar Energy 2004, No76

[17] Kontrec N, Pan ić S, Petrović M, Milošević H.: A stochastic model for estimation of repair rate for system operating under performance based logistics, Eksploatacja i Niezawodnosc Maintenance and Reliability 2018; 20 (1): 68-72, http://dx.doi.org/10.17531/ein.2018.1.9

[18] Kowal M., Korbicz J.: Self-organizing fuzzy Takagi-Sugeno model in the system fault detection (in polish), 6th National Scientific and Technical Conference "Diagnostics of Industrial Processes', Władysławowo, Poland 2003

[19] Lorenzi B., Chen G.: Theoretical efficiency of hybrid solar thermoelectric-photovoltaic generators, Journal of Applied Physics 124, 024501 (2018); doi: 10.1063/1.5022569 
[20] Mahmood, A., Robin, A., \& Sears, M.: Modified residual method for the estimation of noise in hyperspectral images. IEEE Transactions on Geoscience and Remote Sensing, 55(3), 2016, 1451-1460, DOI: 10.1109/TGRS.2016.2624505

[21] Moudgil, P., Bedi, J. S., Aulakh, R. S., Gill, J. P. S., \& Kumar, A.: Validation of HPLC multiresidue method for determination of fluoroquinolones, tetracycline, sulphonamides and chloramphenicol residues in bovine milk. Food Analytical Methods, 12(2), 2019, 338-346, DOI: 6 https://doi.org/10.1007/s12161-018-1365-0

[22] Pluta Z.: Solar energy installations (in polish), Warsaw University of Technology Publisher, Warsaw, Poland 2003

[23] Rajapakse S. (Dept. of Electrical and Computer Engineering, Univ. of Manitoba, Winnipeg, Canada): Simulation of Grid Connected Photovoltaic Systems, Cedrat News, France, Inovallée 2009, No57

[24] Schmid J.: Photovoltaik "Strom aus der Sonne", C.F. Müller Verlag GmbH, Heidelberg, Germany 1994

[25] Skoplaki E., Palyvos J.: A. On the temperature dependence of photovoltaic module electrical performance: a review of efficiency/power correlations, Solar Energy 2009, vol. 83, no. 5, pp. 614-624

[26] Skowronek K.: Electrical circuits in stochastic approach (in polish), Poznan University of Technology Publisher, Poland 2011

[27] Skowronek K., Trzmiel G.: Generalized analysis of the effect of statistical scatter of the elements of photovoltaic matrix on its equivalent dynamic parameters by random values of darkening fields, Post-conference Monograph „Computer Applications in Electrical Engineering", Poznan, Poland 2005, pp. 238-249

[28] Skowronek K., Trzmiel G.: Identification of photovoltaic matrix in real time, AMTEE Advanced Methods of the Theory of Electrical Engineering, Plzen, Czech Republic, 1012.09.2007

[29] Skowronek K., Trzmiel G.: The method for identification of fotocell in real time, ISTET - XIV International Symposium on Theoretical Electrical Engineering, Szczecin, Poland, 2023.06.2007

[30] Trzmiel G.: Determination of a mathematical model of the thin-film photovoltaic panel (CIS) based on measurement data, Eksploatacja i Niezawodnosc - Maintenance and Reliability 2017; 19 (4): 516-521, http://dx.doi.org/10.17531/ein.2017.4.4

[31] Trzmiel G.: Stochastic analysis of the characteristics of the photovoltaic module, PhD dissertation, Poznan University of Technology, Poland, 2010

[32] Trzmiel G.: Verifications of the photovoltaic cell models formulated with the use of multivariable function approximation, IC-SPETO - International Conference on Fundamentals of Electrotechnics and Circuit Theory, Ustroń, Poland, 20-23.05.2009

[33] Vaičiūnas G, Bureika G, Steišūnas S.: Research on metal fatigue of rail vehicle wheel considering the wear intensity of rolling surface, Eksploatacja i Niezawodnosc - Maintenance and Reliability 2018; 20 (1): 24-29, http://dx.doi.org/10.17531/ein.2018.1.4

[34] Van Etten W.C.: Introduction to Random Signals and Noise, John Wiley \& Sons, Ltd, West Sussex, England, 2006

[35] Wang L., Lin Y.H.: Random fluctuations on dynamic stability of a grid-connected photovoltaic array, IEEE Power Engineering Society Winter Meeting 2001, vol. 3, pp. 985-989, doi: 10.1109/PESW.2001.917200 